\title{
Investigating the Adoption of Local Online Communities
}

\section{Claudia López}

School of Information Sciences

University of Pittsburgh

135 North Bellefield Av.

Pittsburgh, PA 15206 USA

cal95 @ pitt.edu

\begin{abstract}
While Internet researchers have largely investigated worldwide information sharing, less attention has been paid to the effect of the Internet on how place-based communities share locally relevant information. My PhD work aims to provide a deeper understanding of the interplay of communities' characteristics and systems' design decisions that affects the adoption, sustainability and impact of local online information systems. My research combines analysis of neighborhoods' publicly available data, user surveys and interviews, content analysis of archival online data, and field experiments. In my dissertation, I will investigate e-Democracy.org, which is one of the oldest and most sustainable attempts to provide virtual spaces for neighborhoods.
\end{abstract}

\section{Author Keywords}

Place-based online communities, User experience design

\section{ACM Classification Keywords}

H.5.m [Information interfaces and presentation (e.g.,

$\mathrm{HCl}$ )]: Miscellaneous.

\section{Research Situation}

I am an information scientist that is in the fourth year of the PhD in Information Science and Technology program. I will take the comprehensive exams in October 2013. I 
believe that attending the doctoral colloquium at $\mathrm{CHI}$ 2014 will be beneficial as an opportunity for social networking with peers and to get valuable feedback about my research agenda. I am looking forward to discussing my proposal design with the colloquium mentors and other PhD students. The timing of the colloquium fits well with my plan to propose my dissertation project in Summer 2014, and to defend my dissertation in Summer 2015.

\section{Motivation}

Although cities and neighborhoods provide a rich context for information sharing and $\mathrm{HCl}$ research [1], many local information systems such as online forums and virtual place-based communities struggle to remain viable over time. The low volume of new content that is generated each day in a local community places burdens on the sustainability of such systems [1]. Lack of enough participation and content has forced several for-profit community sites to close ${ }^{12}$ or become part of bigger multi-purpose systems ${ }^{3}$. Given the potential of online systems to have positive impact on communities [5], investigating the aspects that affect their adoption is relevant for the $\mathrm{HCl}$ field.

\section{Background and Related Work}

Community Informatics $(\mathrm{Cl})$ focuses on community uses of information and communication technologies (ICT) [5] $\mathrm{Cl}$ projects have shown that ICT can help local communities to achieve greater goals such as individual empowerment and social capital [5]. However, these positive results are not consistent across different studies $[5,6]$ and their realization is influenced by the level of adoption of the ICT [6]. Given that $\mathrm{Cl}$ research is mostly

\footnotetext{
${ }^{1}$ http://www. everyblock.com/

${ }^{2}$ http://www.favortree.com/

${ }^{3}$ http://nabewise.com/
}

based on case studies, it has been difficult to compare different results and understand what factors affect the levels of adoption and the impact of $\mathrm{Cl}$ projects [2].

From the designers' perspective, engaging enough contributors and maintaining a reliable stream of content in systems relying on user-generated content is challenging [3]. This is particularly difficult for place-based systems because their potential audience is limited to people who live in or who are visiting at a specific place. Furthermore, creating enough relevant local content to attract this audience is not trivial. The frequency of new local information is generally low (few new items per day) and the community interaction that discusses this information online is often insufficient [1].

\section{Problem, Research Goals and Methods}

Nowadays, it is still unclear what characteristics of the communities and the systems' design affect the adoption, sustainability and impact of local information systems.

This motivates my research questions:

1. What communities' characteristics are associated with the level of adoption of local information systems, and in turn the impact of the systems on the communities?

2. What are the consequences of system design decisions on the online local systems' sustainability?

To address my research goals, I am collaborating with e-Democracy.org, which provides an online public space for neighborhoods "to support participation in public life, strengthen communities and build democracy." ${ }^{4}$ Being active since 1994, e-Democracy hosts today more than 50

\footnotetext{
${ }^{4}$ http://forums.e-democracy.org/about/
} 
local online forums across three countries, including the USA. The fact that e-Democracy provides the same user interface to all their served neighborhoods makes it a proper research platform to investigate which factors affect its adoption and impact on different communities. Figure 1 illustrates the design of my dissertation studies. My dissertation will consist of three studies which combine qualitative and quantitative methods as described below.

\section{Study 1}

The first study is designed to investigate how neighborhoods' characteristics can affect the adoption of the e-democracy forums, and its consequences on the community social capital, and individual and collective efficacy. I will employ publicly available data sources such as census data along with user surveys and interviews to gather information about neighborhoods' characteristics. Among the community antecedents, I will assess aspects such as population size, poverty level, diversity, social capital and collective efficacy. Research in $\mathrm{Cl}$ provides evidence that these factors can influence online community adoption (e.g. [6]).

\section{Study 2}

The goal of the second study is to determine the impact of design decisions on the viability of local systems that rely on user-generated content. I will conduct content analysis of the e-Democracy's archival data in order to investigate the kinds of design decisions organically developed in each forum. Afterwards, I will use statistical methods to model the relationship between these design decisions and the sustainability of e-Democracy forums. This study is informed by my prior studies of other local information systems. My prior work highlighted important factors influencing sustainability of local systems as described below:
Diversity of content: In a study of 16 local Facebook groups associated with four neighborhoods, I investigated the consequences of diversity of content on the subsequent levels of activity in the Facebook groups [4]. Contrary to findings on the negative consequences of diversity on large-scale systems, I found that in local groups, diversity of the information was beneficial because it led to a sufficiently active content stream, which in turn helped the groups remain viable over time.

Multiple goals strategy and flexible local communities' boundaries: Through a longitudinal content analysis of the information posted in 21 community paper-based bulletin boards located in five neighborhoods, I found that their viability is built upon several design strategies.

Among them, a dual strategy of encouraging a sense of community as well as supporting information discovery, and using a flexible definition of the neighborhoods' geographical boundaries contributed to their viability ${ }^{5}$.

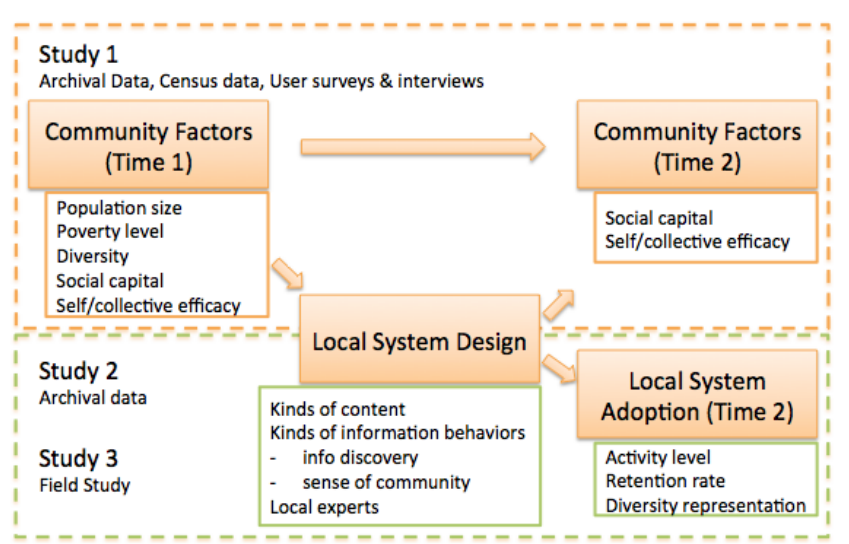

Figure 1: Proposal design

${ }^{5}$ This work has been submitted as a work-in-progress to CHI 2014 
Role of local experts: In a study of a large dataset of Yelp online local reviews, I found that local expertise is associated with providing more useful reviews. This result is encouraging as it hints that engaging local experts in contributing to local information systems is a viable strategy to gather valuable content ${ }^{6}$.

Study 2 will allow me to generalize my previous findings beyond one kind of local systems in a larger sample of neighborhoods. It will also identify pertinent design factors related to the sustainability of e-Democracy forums.

Study 3

The goal of the final study is to assess whether any of the associations tested in Study 2 embody a causal relationship. I will design and conduct an experimental field study in which influential factors identified in Study 2 will be manipulated in e-democracy forums. To avoid harming a real system with potentially negative manipulations, the control condition will be designed as the existing state of the system. The experimental condition will showcase the factors we identified to have positive associations with adoption and sustainability. For example, if the positive effect of content diversity is confirmed, I will study this relationship by exposing a random set of E-Democracy forum users to content which has been manipulated to showcase higher diversity.

\section{Dissertation Status}

I am currently designing the dissertation proposal. I will conduct Study 1 and Study 2 in Fall and Spring 2014.

Their results will better inform the design of Study 3. In the DC, I would like to receive feedback about the design of the field study, which will be conducted in Fall 2015.

${ }^{6}$ This work was accepted in Web Science Track, WWW 2014

\section{Expected Contributions}

My research agenda aims to expand $\mathrm{HCl}$ research to 1 ) understand the adoption of social online systems by investigating the characteristics of the targeted groups instead of the characteristics of particular individuals; 2) assess the consequences of different design decisions on the viability of social online systems for local communities; 3) apply $\mathrm{HCl}$ methods such as correlational analysis of archival data and field studies to contribute to other disciplines such as $\mathrm{Cl}$ and Information Behaviors. My work has implications for technology developers seeking to create sustainable local information systems and urban planners aiming to increase residents' participation online.

\section{References}

[1] Carroll, J. M., and Rosson, M. B. Wild at home: The neighborhood as a living laboratory for $\mathrm{HCl}$. ACM Trans. Comput.-Hum. Interact. 20, 3 (2013), 16:1-16:28.

[2] de Moor, A. Moving community informatics research forward. The Journal of Community Informatics 5, 1 (2009).

[3] Kraut, R. E., and Resnick, P. Building Successful Online Communities: Evidence-based Social Design. Cambridge, MA: MIT Press., 2012.

[4] López, C. A., and Butler, B. S. Consequences of content diversity for online public spaces for local communities. In Proceedings of CSCW '13, 673-682.

[5] O'Neil, D. Assessing community informatics: a review of methodological approaches for evaluating community networks and community technology centers. Internet Research 12, 1 (2002), 76 - 102.

[6] Williams, K., and Durrance, J. Social networks and social capital: Rethinking theory in community informatics. The Journal of Community Informatics 4, 3 (2008). 